\title{
Between Disciplinary Power and Care of the Self: A Dialogue on Foucault and the Psychological Sciences
}

\author{
Cressida J. Heyes and Chlö̈ TAylor
}

Cressida Heyes is Professor of Philosophy and Canada Research Chair in Philosophy of Gender and Sexuality at the University of Alberta. She is the author of Line Drawings: Defining Women through Feminist Practice (Cornell University Press, 2000), and of Self-Transformations: Foucault, Ethics, and Normalized Bodies (Oxford University Press, 2007). Her latest work addresses how sex and gender norms are rewritten as normal and abnormal states of mental health, and the body as a site and expression of freedom. Chloë Taylor is Assistant Professor of Philosophy at the University of Alberta. She is the author of The Culture of Confession from Augustine to Foucault (Routledge, 2009). Her two current projects explore sexual crime and prohibitions, and dietary normalization, from feminist and Foucauldian perspectives. This dialogue emerges from a shared curiosity about Foucault's hostile relationship to the psy disciplines, and how the content and method of his critique might be mutually informed by feminist theory.

CT: You describe your article, "Diagnosing Culture: Body Dysmorphic Disorder and Cosmetic Surgery," as "part of a scholarly trend that aims both to historicize psychiatry's more essentialist claims and to challenge the contemporary pathologization of individuals and the depoliticization of medical practice" (78). You begin this paper by citing Susan Bordo's description of psychopathology as the "crystallization of culture" and relate this statement to a Foucauldian point about the relation between the normal and the abnormal. Can you explain how you see Body Dysmorphic Disorder (BDD) as a symptom of our culture as well as the relation between this abnormal condition and what you call at one point in the article a "norm of femininity"? 
$\mathrm{CH}$ : I need to back up a little to show how I answer that question. This article started as a rather exasperated response to a psy literature that one constantly comes across when doing research on cosmetic surgery. It's a literature that is trying to answer several very important related questions: what motivates individuals to consider having, or to have cosmetic surgery? What does cosmetic surgery do to or for those who have it? The answers to these questions are, as you might expect, very diverse and ultimately hard to generalize. However, what came to interest me more, in Foucauldian spirit perhaps, were the conditions of possibility of framing these questions. Specifically, the literature clearly assumes that its epistemological mandate includes dividing people up on the basis of characteristics peculiar to individuals, and one key actionguiding question is: how do we know who is a good or bad candidate for cosmetic surgery? What sorts of people thrive post-surgery, and what sorts of people regret it, for example? But if one spends any time in the cultural milieu that is what I call "the cosmetic surgery industry," one notices that of course thinking about (having) cosmetic surgery, looking at the technical possibilities on other people (like before and after pictures), reading narratives by nervous prospective or satisfied customers, and so on, also creates a subjectivity. In my experience (and I'm not the only one), this subjectivity is characterized mostly by a growing knowledge of and anxiety about one's physical flaws. And, of course, being hyper-aware and anxious about appearance is also a culturally normative subjectivity in North America, especially for women. So exposure to the cosmetic surgery industry (something that's almost impossible to completely avoid now) intensifies one psychological aspect of normative femininity - and, of course, this is absolutely necessary for the marketing of cosmetic surgery. If we were all really happy with how we looked, then there wouldn't be an industry! Cosmetic surgeons like to say they are culturefollowers, not culture-makers, but I think they are clearly both, especially to the extent that they 
innovate to create new techniques that are mutually constitutive of new flaws, and represent the body as an aesthetic object to be ever-more closely scrutinized. So cosmetic surgery both relies on and contributes to a culturally specific norm of femininity, thus understood.

So far, so obvious, really. Another player in this same literature is Body Dysmorphic Disorder. The primary symptom of BDD is "excessive" anxiety about appearance. What makes it "excessive"? Basically if it makes you very distressed or interferes with your normal work or social "functioning." But adequate "functioning" depends on your context—your class status, your work life, other people's expectations of you, how much you expect of yourself, and so on. And how much distress about your physical flaws is too much? These are very subjective criteria, and the diagnosis is always going to be both contextual and strategic. That's partly why the clinical literature - and perhaps even more the self-help literature - relies quite heavily on descriptions of extreme cases. (And, of course, if I were a treating psychiatrist, I'd be very eager to try to help people who are so profoundly anxious about their "normal" bodies that they perform auto-surgery, or never leave the house, or attempt suicide.) However, people who are "normatively" anxious about their appearance-like the anti-heroine of the popular "chick-lit" books Bridget Jones - are only divided from "pathological" types by context and subjective assessment. So the pathology here is a "crystallized" (i.e. reified and hence visible in the larger solution of culture) form of a subjectivity that, pace my first point, cosmetic surgery itself cultivates. Thus a second move in the article is to suggest that rather than being (only) a pathology caused by features inherent to abnormal individuals, BDD marks the severe end of a spectrum of normative lived experience that has big-picture causes. Most people writing in the psy literature do pay lip-service to this (also rather obvious) conclusion; they include short paragraphs or token chapters on "the social causes of BDD." These texts are very thin indeed by 
the standards of critical work in the humanities. They have a uniform narrative trajectory: we do indeed live in an appearance-preoccupied culture, they state, and that might cause a sort of diffuse anxiety. We can wave a hand at "the media" to describe the source. But socio-cultural explanations cannot account for why some individuals develop BDD while others do not. End of story. Of course it's true that any social theory underdetermines an individual's experience, but it's possible to have a theory that integrates the two-indeed, most of social theory tries to do just that! And, as traditions of feminist therapy, for example, show, it's also possible to have a practice of working with individuals that integrates their personal suffering with a contextual, political understanding of some of its origins. So the psy sciences are very depoliticized with regard to BDD.

Bringing the two points together, in the course of my research, I came to realize that the very slipperiness of the BDD diagnosis is useful for cosmetic surgeons. BDD is a “contraindication" for cosmetic surgery_BDD sufferers are definitely "bad" candidates, mostly because (in this discourse) they are rarely satisfied with their surgical outcomes, and tend to blame surgeons for not fixing their faults, or have more and more surgery, never being satisfied. Surgeons don't like patients like this: they tend to complain, sue, or maybe turn into so-called surgery junkies like Michael Jackson or Joyce Wildenstein and give cosmetic surgery a bad name. Sometimes these responses even seem to be taken as evidence of BDD retroactively and used to de-legitimate the complaint: “of course she didn't like her results and is suing me for malpractice; she has BDD!" So there's a strategic motivation for the diagnosis that gets (not very successfully) covered up with talk of ethical practice with regard to the mentally disordered. My most politically interesting conclusion was thus that BDD functions in the context of cosmetic surgery not only as a "contraindication" (as if cosmetic surgeons ever really check out the mental 
health of their prospects all that carefully) but as a diagnosis that creates a language for objectifying difficult people.

CT: You make the point in your article that there is a similar relation between eating disorders and "normal" dieting practices. Can you explain?

$\mathrm{CH}$ : This point comes out of earlier work I did on Weight Watchers. If you are on a diet you are supposed to stick closely to a regime that typically involves close monitoring, measuring, and restricting of everything you eat and drink, and perhaps how much you exercise, or even what your mental habits are. All this is done in the name of physical health, because the goal is (almost always) weight loss, which is assumed to be a good for almost all of us. And, to the extent that body fat is commonly understood as a sign and symptom of some negative mental state - whether greed, or lack of self-discipline, or low self-esteem (to name three quite different models) — if you lose weight, you'll both demonstrate and improve your mental health, too. But if you look at the symptoms of eating disorders - and anorexia compares most closely to weight loss dieting - that too involves monitoring, measuring, and restricting in the name of losing weight, only in this case it "goes too far" and the practices become obsessive-compulsive and the sufferer becomes too thin. In fact, anorexia commonly starts as a successful conventional diet, which then turns into a runaway train. So the analogy was just making that point: wanting to look good and engaging technologies of the self to do so is normatively feminine and thus indicates mental health (on the logic of this model), while "going too far"-developing BDD or anorexia-crosses a line marked more by degree than kind of symptom. In both cases we have significant cultural resources devoted to cultivating the symptoms that the same culture will 
pathologize if they exceed what we can tolerate. (That idea of toleration is under-theorized, but the threshold for it shifts all the time in response to cultural trends. Thirty years ago someone like Sarah Jessica Parker would have been seen as repulsively, pathologically thin, whereas today she's a fashion icon.)

CT: In a particularly fascinating section of the article, you show that the "normal" cosmetic surgery patient has a normatively feminine psychology (anxious about bodily flaws but nondemanding, deferential to the doctor, easily satisfied, etc.). At the same time, you have shown that there is no "bright line" between this patient and the abnormal (mentally ill, overly-anxious, BDD-afflicted) patient. In some sense, then, the patient with BDD seems to suffer from a failure of femininity, but on the other hand she is excessively feminine. Is there a tension here?

$\mathrm{CH}$ : Her failure to be deferential and her anxiety are the same thing: she's not "reasonable" about what she can expect or in being satisfied with what she got, and that's because she's excessively anxious-where "excessively" means that surgery can't assuage her negative feelings. It's circular. And we can't say, “operate only on people who aren't at all anxious about their physical flaws," because such people don't come forward for cosmetic surgery in the first place. (I footnote an unintentionally funny promotional video by a woman plastic surgeon in Canada who basically says, "I only do cosmetic surgery on people who feel good about themselves." She's obviously highly risk-averse!) So often I see surgeons as walking a tight-rope: how much anxiety is normal, motivating? How much is crazy? (As an aside, a disproportionate number of men get treatment for BDD, and that fact is often adduced in support of a biomedical etiology: there's so much more pressure on women to look good, yet a lot of men have this mental disorder, so it 
must be individual rather than cultural. But we could speculate differently: women get to have a higher level of psychological impairment, culturally speaking, before their mental state is considered disordered.)

CT: BDD would be similar to masochism in that respect. Freud calls one type of masochism "feminine masochism," and yet he only discusses cases of men who suffer from this kind of masochism. Women who conform to this diagnosis in men would be relatively normal.

You mention Foucault's account in Abnormal of mental dysfunction coming to be related to involuntarism or a failure of the will, and what this means for cosmetic surgery: it is precisely individuals who cannot will themselves to ignore bodily "flaws" who will be good candidates for cosmetic surgery, but these same individuals will most likely be deemed to have a mental disorder, and thus be bad candidates for cosmetic surgery. Can you explain your views on cosmetic surgery as a "psychological cure"?

$\mathrm{CH}$ : I don't think it really works. At least, it seems to make some people feel better in a fairly local and often short-term way, but the motor of cultural disdain for bodily imperfection has been ratcheting itself up for some time, and of course we all get older, so even the most well-adjusted user of cosmetic surgery has to keep on having it in order to stand still. Some people have a very specific, intersubjectively validated preoccupation and only want one surgery to fix it (an enormous nose, for example); if that goes well, they may be done. But having one cosmetic surgery is one of the indicators that you'll be likely to have more: it gets demystified, especially if the results are as you expected (it helps to have low expectations). Some people like aspects of the process: getting serious attention paid to your anxieties by medical staff, the feeling of taking 
charge of your life, or even general anesthesia. Therefore there is no "cure" in the sense of a permanent end to dissatisfaction with our bodies; it's not like the "cure" of a surgery that repairs a hernia or removes an appendix.

I've been struck by how un-curious feminists seem to be about these empirical questions of whether cosmetic surgery "works" in alleviating psychological suffering for individuals. I suspect feminists often implicitly assume that it's a panacea we have to resist because it's a tool of a patriarchal culture. To me, if true, that's advocating martyrdom. If cosmetic surgery is a panacea, then we should be working, as feminists, to make it more accessible to everyone! A few marginal people defend this position, but it isn't taken very seriously, because most feminists recognize there is a systemic problem. The relation of individual and system is under-theorized, though: I wish more feminist psychologists were doing politically savvy research on what makes particular women more resilient in the face of the cosmetic surgery industry, and what cultivating resistance looks like (there's a use for psychology!).

CT: This paradoxical relation of psychiatry to surgery arises again with respect to sex reassignment surgery as a treatment for so-called Gender Identity Disorder (GID), which you have discussed in your 2007 book Self-Transformations. Can you say something about your view of the role of psychiatry in the case of GID and sex reassignment surgeries?

$\mathrm{CH}$ : This is a fascinating and very under-explored connection. I've got an unpublished paper that tries to thrash out the difference between GID (a diagnosis which is a necessary condition of getting access to sex reassignment surgery [SRS], in most contexts) and BDD (which is, if diagnosed, a contraindication for cosmetic surgery). There's tremendous resistance in the trans 
world to even mentioning these two things in the same breath, because separating SRS from cosmetic surgery is taken to be rhetorically crucial in getting the former funded by state healthcare plans. Almost no state healthcare system in the world pays for cosmetic surgery per se (the Netherlands had a brief dalliance with the idea, and Brazil has a vast cosmetic surgery industry that is state-sponsored and has all the anthropologists in the world converging on it!), although procedures that are considered "reconstructive" are typically covered (another interesting and controversial distinction). SRS is always presented as "medically necessary," and that phrase implies, in this discourse, that there is a diagnosis paving the way. No identifiable physical symptom distinguishes transsexuals as such, so their diagnosis has to hinge on some shared psy state. That state is often (although not always) experienced and represented as completely out of their control and not amenable to any talking cure; this ties in with the previous question, because this model of transsexuality really stresses its utterly involuntary nature - it's essential to you, you can't be talked out of it, only sex change can treat you. There's a comparative historical paper to be written about how this model came to be, when set against the history of cosmetic surgery, in which the "inferiority complex" was very significant in the first half of the twentieth century, but has dropped out of view as a contemporary mental disorder.

I know you've been thinking yourself about some of Foucault's Collège de France lectures on the history of psychiatry, and their uptake by Anglo readers. In particular, we read Ladelle McWhorter's historical analysis of racism together. Can you say how you think that material relates to this discussion? 
CT: In the last lecture of his 1975 lecture series, Abnormal, Foucault argues that psychiatry is racist and bound up with what he calls "racism against the abnormal." Abnormal traces the emergence of the concept of abnormality in psychiatric discourse and practice. In particular, it examines the ways in which psychiatry transitioned from imitating medicine, or from treating mental pathologies, to managing abnormalities - racial or ethnic "abnormality" being one example. Foucault considers how this transition from a psychiatry of mental illnesses to a psychiatry of abnormalities entailed a vast, and ultimately racist, expansion of psychiatry's power. McWhorter, like Foucault, is concerned to track the history of the eugenics movement as it is deeply embedded in psychiatry and the psy disciplines more generally. McWhorter and Foucault don't seem to think that psychiatry just happened to get mixed up with racism during an unfortunate period in history, but that it, like biopower, is almost inherently racist. It is normalizing, and one norm in which it is invested is racial. Something that I am interested in doing in the future is writing a genealogy of speciesism, similar to Foucault's and McWhorter's genealogies of racism, but also showing how the racism of which Foucault and McWhorter provide a genealogy is itself speciesist. I want to discuss the ways in which speciesism and an animal-based diet are norms to which we are disciplined to conform. In the extreme case, people who diverge from these norms can be psychiatrized: in Abnormal, Foucault discusses the nineteenth-century diagnosis of "anti-vivisection syndrome," and I am interested in other, more or less subtle ways in which we pathologize those who resist speciesism: "crazy cat ladies" and the "queerness" of vegetarianism in the popular imaginary for instance.

$\mathrm{CH}$ : You are also working on a new paper on feminist sexological responses to the American Psychiatric Association's Diagnostic and Statistical Manual diagnosis of Female Sexual 
Dysfunction (FSD). How has reading Foucault helped you think about this category of mental disorder?

CT: Reading books by sexologists on the topic of FSD, I am wondering if we have to take the history of psychiatry that Foucault traces in Abnormal one step further, and say that psychiatry shifted not just once, at the end of the nineteenth century, from treating pathologies to managing abnormalities, but again, at some point in the late twentieth century, from managing abnormalities to intervening in conditions that are not even abnormal (in the sense of unusual), but are simply considered undesirable. According to a 1999 National Health and Social Life Survey, published in the Journal of the American Medical Association, FSD (which includes hypoactive sexual desire disorder, sexual arousal disorder, orgasmic disorder, and sexual pain disorders) afflicts American women at the rate of $43 \%$ (compared to $31 \%$ of men who suffer from Male Sexual Disorder) and more than $50 \%$ of women over the age of 40 . As with BDD, the very subjective marker of "distress" is used to determine whether a low libido or delay in orgasming is disordered or not. In one case study, a mother with four children was still having sex several times a week with her husband, but her husband thought this wasn't enough and his resentment was causing stress in their marriage; the wife was diagnosed with FSD. One thing that disturbed me the most when reading case studies such as this was how often it was actually the woman's male partner who was “distressed”- - frustrated, angry—about the woman's sexual functioning, and the woman's distress was only a reaction to his, but nevertheless resulted in the woman being diagnosed with FSD, treated with psychotherapy and prescribed testosterone and Viagra. 
The $43 \%$ statistic is cited throughout the literature and is used to stress the urgency of the problem posed by FSD and the need to get Federal Drug Administration approval for a drug to treat a disorder impacting so many women's - and men's!-lives. What strikes me about this statistic, however, is the fact that there is a psychiatric diagnosis for conditions that are not, statistically speaking, abnormal at all, and that, in the case of women over 40, even reflects the majority. Lower libido after menopause is not "abnormal," for instance, but it is still considered "disordered" and "dysfunctional" if it is causing distress, including marriage stress. The sexologists whom I am reading repeatedly make the point that one of their first goals in treating FSD patients is to reassure them of their "normalcy." They are not crazy, they are not weird, they are not alone, many women suffer from the same problem, and yet these women are still considered to be afflicted with psychiatric and/or medical disorders requiring a broad range of psychotherapeutic, surgical, and pharmacological treatments. I think this may be representative of a larger trend, whereby psychiatry has now "dispensed" not only with illness (as Foucault says) but also with abnormality, and now treats even the normal. If that's right, it seems that it has expanded its web of control yet again. The pathological are a small group, the abnormal constitute a larger group, and now even the normal require psy treatments. The casualness with which people now discuss their therapies also suggests that we no longer think that psychiatry, psychology, and psychoanalysis are reserved for the abnormal-one can admit to going to psychotherapy without being considered abnormal today.

$\mathrm{CH}$ : I'd say a couple of things about this. First, you seem to be using "abnormal" here solely in the sense of "uncommon." I agree that one way Foucault uses "abnormal" is to refer to individuals who seem destined for atypical — especially degenerate-developmental paths, so in 
that sense it is noteworthy that the technologies once used to manage "deviance" are now being applied to (or taken up by) individuals who are not abnormal in this sense. But it seems as though an implication of the developmental model that Foucault takes to be central to disciplinary power, to eugenics, to "racism," and so on, is that everyone deviates from the norm in some respect, or to some degree. So, second, no one is actually "normal," because the normal comes to be a fantasy, a regulatory ideal rather than a description of actual persons. It becomes institutionally and conceptually possible for smaller and smaller deviations to be taken as objects of intervention. What you describe with regard to FSD, and more generally, seems to be evidence of something right about Foucault's analysis of psychiatric power: because abnormality is both a relative concept and only a matter of degree, we are all, eventually, abnormal. That gloss, however, covers over a host of other issues: much of what you describe as the new power of psychiatry, for example, is also bound up with its appropriation by a bourgeoisie very preoccupied with its own psychological welfare, when clearly our struggles have larger political contexts. Furthermore, one might think that being reassured that one's negative sexual experience is very common in a cohort would be an incentive to start a support group, at least, rather than go for drugs or surgery. Whatever happened to feminism?

CT: Yes, FSD remains an "abnormal" condition in the sense that it deviates from a regulatory ideal of female sexuality that is a social (male) fantasy. Susan Bordo has said that men are now more threatened by women who don't enjoy sex and who don't have orgasms than by women who do, contrary to a nineteenth-century norm of female sexuality. We can see this shift in pornography: nineteenth-century pornography didn't have to show women loving intercourse, whereas today this is essential to the male fantasy. So now we have a diagnosis for women with 
supposedly low libidos and with so-called "orgasmic disorders," as violators of the new norm of female sexuality according to which women should always want sex (with men) and should be easily satisfied — indeed blown away — by it. Clearly this is a contemporary male fantasy and all women will be more or less abnormal with respect to it, rather than any majority representing the norm.

Nevertheless, when Foucault discusses a psychiatry of the abnormal that emerged in the late nineteenth century, I do think it is interesting that the people it targeted were "abnormal" in both the statistical sense and in the sense of deviating from a regulatory ideal, and that these two had to go together whereas now they are coming unbound. Nineteenth-century psychiatrists "discovered" new conditions, including agoraphobia, claustrophobia, kleptomania, homosexuality, masochism, and antivivisection syndrome, and the problem psychiatrists had with the people afflicted by these conditions was clearly a "moral hygiene" problem. It wasn't just that these nineteenth-century personages were rare that made them targets, and yet they were rare compared to the people they were opposed to (those who are not afraid to leave the house, or to be in a confined space, etc.), and I think that the psychiatrists could not have gotten away with presenting these as "health problems" if they had not been statistically as well as ideologically abnormal. What interests me about FSD is that psychiatry no longer needs to present the deviance in question as contrary to a natural or biological norm. Psychiatry can now be more upfront about its role—which Foucault identified — as manager of regulatory ideals. Maybe this is a reflection of how unquestioned psychiatric power is today, that it no longer needs to be duplicitous about what it is up to. 
$\mathrm{CH}$ : I wonder whether the example of FSD doesn't raise another challenge. We know that Foucault's work has many theoretical and political lacunae when it comes to feminism. He talks about some controversial figures in the history of psychiatry-the hysterical woman, the pedophile - in ways that feminist thinkers have criticized. Do you think that Foucault's critique of psychiatry has particular value or particular pitfalls for feminist thought?

CT: In The History of Sexuality Foucault describes the hystericization of the maternal body under biopower as something that women were subjected to; however, true to the maxim that "where there is power, there is resistance" in Psychiatric Power, Foucault writes of "the hysterics, those famous, dear hysterics," as a "front of resistance" to disciplinary power (253). As for the pedophile, I don't think Foucault ever talked about a pedophile. When feminists say that Foucault defended a pedophile-Charles Jouy-they are missing the point of that example, because Foucault's whole point is that Jouy was not a pedophile, that sexuality wasn't an identity at the time that Jouy raped an adolescent girl (the version of events that we get in Abnormal, as opposed to volume 1 of The History of Sexuality, suggests that the "bucolic pleasures" in question were in fact a rape). Foucault's point is that Jouy didn't rape Sophie because he was into underaged females, but because of his particular context in life, being too poor and marginalized to be able to marry or even attract women his own age. Foucault's argument is that Jouy raped the particular individual that he did, not because of an an intrinsic sexuality (as the doctors assumed), but at least in part due to a particular set of circumstances (Foucault tells us how much Jouy was paid, what kind of work he did, what kind of social life he had, what kind of place he lived in). Nineteenth-century psychiatrists, however, were not interested in Jouy's circumstances in life, but rather assumed that Jouy's act must reflect a type of being that was 
inscribed on his body - hence they measured his brainspan and subjected him to other physical examinations, and kept him locked up for the rest of his life, sure that he would recidivate if released because recidivating would reflect his very essence. Foucault is using this case as an example of the perverse implantation, of the construction of sexualities. For some reason people have gotten that argument when it comes to homosexuality, but not with respect to the Jouy example. I think Foucault is not defending a pedophile so much as he is showing how pedophilia came to be constructed and resisting that construction. This is not to say these are not highly problematic passages in Foucault's oeuvre - he is defending rape as a trivial pleasure, and he is clearly more concerned with Jouy than Sophie. But these passages are not about a pedophile: they intend precisely to show that Jouy was not a pedophile, unless the psychiatrists were successful at turning him into one. They argue that pedophilia was coming to be constructed as an identity at that very moment in history, and Jouy was an early victim of that construction. I think we should take Foucault's argument very seriously when we think about our approach to sexual crimes, even if we definitely need to throw out the sexist aspects of Foucault's argument. This is what the book I am currently writing aims to do: explore a feminist-Foucauldian approach to sex crimes. I think that the sexist aspects of Foucault's discussion of the Jouy case can be disaggregated from his claim about sexual identities, or that they reflect "Foucault the man" and are not intrinsic to his philosophy. I think that it is really unfortunate that the sexism of Foucault that is very apparent in this example has led people to dismiss the entire discussion, rather than to see what is crucial about it for our own times. I think we can take up what is useful about his argument and dispense with the sexism, and that is what I am aiming to do.

As for the case of FSD, I think it clearly calls out for a feminist response and that Foucault can help us with this response. Feminist sexologist Leonore Tiefer has started 
something of an anti-FSD feminist movement and claims to be theoretically inspired by Foucault, whom she invokes whenever she wants to tell us that sexuality is "socially constructed" and that the FSD diagnosis is social construction in action. The problem with Tiefer is that while she recognizes that the FSD vision of sexual health is "socially constructing" female sexuality according to a masculine model, she contrasts this with what she thinks women really want from sex, which is not frequency and orgasms but communication, intimacy, flattery, eyecontact, chocolates, flowers and spiritual connection. She doesn't seem to realize that this is also a social construction of female sexuality. What's funny is that both the Tiefer camp and the opposed, pro-FSD sexology camp present themselves as feminist-as "new" and "revolutionary." You have self-described feminist sexologists like Laura and Jennifer Berman describing the medical treatment of FSD as "feminism's next frontier," and arguing that this is a revolution in which women are finally insisting that the male-dominated medical profession take female sexuality as seriously as they take male sexuality. They are prescribing Viagra and testosterone to their female patients, and think women want the exact same things from sex as men. They include diagrams of the clitoris showing how it is just like the penis. Then you have Leonore Tiefer's group arguing that they are the feminist revolution in the FSD controversy, but their view of female sexuality seems to be little more than the cliché whereby men want sex and women want romance, men want orgasms and women want compliments.

While Tiefer doesn't quite get it, I do think that Foucault's critique of psychiatry and of the medicalization of sexuality are useful to this feminist debate. I think we can use Foucault's critique of the medicalization of sexuality to resist the entire discourse of "sexual dysfunction" as it applies to male sexuality as well as to female sexuality. The alternatives he posed to the medical model of sexuality were the Eastern ars erotica and the ancient Greek and Roman 
aesthetics of the self: art rather than science in both cases. What would it mean to dispense with this medical discussion of what female sexuality and male sexuality are, or should be, and to instead approach sexuality aesthetically? While the two most common questions that people ask sexologists are "am I normal?" and “is my partner normal?", we don’t want artworks or artistic performances to be "normal." We want art to be extraordinary, and to demonstrate skill rather than to reflect nature. Tiefer also suggests that we approach sex as a form of creative selfexpression, more like music than a set of medical norms, however she has a clear "script" as to what this creative self-expression should express (romance, eye contact, compliments, spiritual connection). I think we can take up Foucault's suggestion of an aesthetic approach to sexuality in more interesting, or at least non-normative, non-essentializing ways.

On the other hand, I am not sure that just because Foucault consistently critiques psychotherapies as disciplinary, we, as feminist theorists, need to believe that they can only ever function that way, or that there are no resources in Foucault's works that we can use to approach the psy disciplines otherwise. Weight loss dieting has been described by feminist scholars such as Sandra Bartky as disciplinary. Women in particular internalize a panoptic and patriarchal gaze and come to self-monitor their alimentary intake in order to conform to bodily norms in a way that eventually seems voluntary or self-imposed, masking and thus facilitating their subjection to power. In Self-Transformations, you have nuanced this argument, demonstrating that weight loss dieting programs can be simultaneously understood as technologies of self care. For instance, you compared Weight Watchers' pamphlets to the hupomnêmata of the Ancient Greeks described by Foucault. I am wondering if we might say something similar about psychotherapies, including sex therapies. Foucault describes the psy "sciences" as uniquely disciplinary; only in The Hermeneutics of the Subject does he compare technologies of the self (such as Ancient 
Greek master-apprentice relations) to psychotherapies, and this seems very tongue-in-cheek. Yet, in all seriousness, Foucault scholars such as Helen O'Grady have described (feminist) psychotherapies as technologies of self-care (Woman's Relationship). Such therapies, she argues, are means by which women might transform themselves into more autonomous, less-disciplined, less-gender-oppressed subjects. While psychotherapies, like dieting, could be taken as paradigmatic examples of disciplinary power, it also seems accurate to say that most people undergoing such treatments see these practices more as technologies of self-care and selftransformation than as disciplinary. Arguably, specifically feminist psychotherapies might be self-transformative in non-normalizing ways. Individuals submit to these treatments—apparently voluntarily — because they want to become different kinds of subjects. Of course, for Foucault we can't take people's intuitions about why they undergo psychotherapies at face value, we need to grant that the kinds of self-transformative goals or desires with which one enters psychotherapy (like those one brings to Weight Watchers) may themselves be the effects of normalization. But this complicated picture, which would vary from case to case depending on the kind of treatment and the motives of the participants, seems quite similar to your account of weight loss dieting.

In response to this, would you say that the apparently voluntary choice to undergo psychotherapeutic treatment merely demonstrates the degree to which we have capitulated to normalization and internalized the psychiatric gaze, or would you say that the intuitions of people undergoing these therapies (that they are simultaneously caring for and transforming themselves) is correct? 
$\mathrm{CH}$ : I would say that both are true. I know that this sounds like a cop-out. What voluntary "psychotherapeutic treatment" actually entails is tremendously variable: are we talking about someone who's desperate to avoid being institutionalized and sees their authoritarian psychiatrist as the drug-dealer they have to negotiate with, or someone who attends a twelve-step program for the peer support, or someone who's found a very egalitarian feminist couples' therapist to work through their relationship problem? I'm not sure that we can continue to talk as if "psychotherapy" is a single thing. Therapeutic techniques are more and less normalizing, and an individual therapist can be more or less normalizing in their practice. Some can be supportive of attempts to resist the negative aspects of normalization. Reflecting on one's self, and using another person as a dialogic partner or helper is such a general human practice that I'd hesitate to just label all psychotherapy as "normalizing." Because of my political commitments, which Foucault has helped me to arrive at, I am personally more attached to therapeutic modes that make their own presuppositions visible and that take the emerging relationship between therapist and client to be an object of discussion. Therapists who won't talk about counter-transference or power are useless to me. But I have a lot of educational and financial privilege, and my mental health is (defined as) good enough that I can negotiate these things. Most people using mental health services are vulnerable and don't have many resources or choices. So I guess all possibilities in answer to that question are open.

Foucault's critique of psychiatry targets something in therapeutic relationships that is, in my view, both very specific and under-specified, which makes it hard to work out exactly what model of psychotherapy he's objecting to, and why. 
CT: John E. Toews has argued that Foucault's critique of psychoanalysis "operate[s] at a very high level of abstraction, and there is a danger in that. The self-reflective and critical dimensions of psychoanalytic texts are often lost, or perhaps denied, in this reduction to discursive regularities" (31). So it seems that you would agree with this claim, or that you think that psychoanalysis, both as a theory and as a practice, is more sophisticated and self-reflective than Foucault gave it credit for.

$\mathrm{CH}$ : Yes, I do. In fact, Foucault's critique seems to have become more and more oblique as his career progressed-from his first, later-repudiated writings in psychology, to the explicit but ambivalent engagement with Freud in Madness and Civilization, to the attack on the repressive hypothesis in History of Sexuality, which implies that psychoanalysis is a contemporary form of confession without seriously considering the differences between them. Foucault almost never engages the specialist vocabulary of particular psychoanalytic models, or considers the breadth of psychoanalytic influence that was felt in his own lifetime. I still think we need fine-grained and sophisticated languages for talking about the development of individual psychic life in mutual relation with political life. But I haven't thought enough about Foucault's relationship to psychoanalysis to say more.

Maybe I can turn this question back to you. Your first book is on Foucault and confession: what do you think of Foucault's situating of psychoanalysis within his critique of confession? Why, in general, do you think Foucault was so hostile to psychiatry, and so consistently preoccupied, in his writing, with that hostility? 
CT: In The Culture of Confession, and then more extensively in an article I wrote on Frantz Fanon and Foucault, I argue that Fanon shared many of Foucault's insights into psychiatry and yet this did not result in the same categorical hostility towards the discipline on his part. Fanon recognized that apparently gentler forms of power might supplant brutal displays of force, not because those involved in these power relations became more humane, but because they found them to be more effective. He is discussing the shift from earlier to later stages of colonization, rather than the history of the prison or the asylum, but he recognizes that an internalization of colonial norms takes place and results in colonized-we might say docile-bodies. He also recognizes the role of psychiatrists in this colonial task: Fanon, like Foucault, notes the historical connections and overlap in personnel between psychiatry and the police, doctors and torturers. Most importantly, he recognized that psychiatry was politics passing itself off as science, or that psychiatrists exploit their scientific authority to enforce social, political, and moral norms. And yet these insights did not prevent Fanon from practicing psychiatry. Rather, recognizing the political rather than scientific nature and power of the psy disciplines enabled Fanon to effectively take up psychiatry and, to a lesser extent, psychoanalysis, as political tools. He also radically transformed the ways that psychiatry was being practiced in the hospitals where he worked.

In practicing psychiatry and writing about psychoanalysis, Fanon declares his political bias. In The Wretched of the Earth, he includes a series of case studies from his psychiatric practice, but he prefaces them by saying, "It is superfluous to mention that we are not providing a scientific work" (241). He also announces that he cannot be objective, that he is politically invested in what he is writing about. All this seems very similar to what Foucault says, in "Nietzsche, Genealogy, History," about the genealogist announcing his political biases, not 
claiming to be objective, using history as a political tool or a weapon. So, for me, this raises the question: Why didn't Foucault have a similar attitude towards psychiatry as he had towards history? Why can't one admit the politically-invested nature of psychiatry and take it up for positive ends, as Fanon arguably did, at least with respect to decolonization?

In my paper I point out that while Fanon is anti-colonial in his psychiatric practice, he was also sexist and heterosexist and exploited his psychiatric power to diagnose homosexuals and women who didn't conform to his fantasy of femininity as abnormal, disordered, unhealthy, disgusting, and pathetic. At least in the case of homosexuality, he was quite open about his reaction being an emotional rather than a scientific one. So he recognized how psychiatry was functioning as a normalizing politics rather than science in the case of colonization, but this didn't stop him from being complicit in more and less self-conscious ways in similar kinds of movements when it came to the disciplining of women and non-heterosexuals. Nevertheless, we can imagine a psychiatry that was simultaneously anti-colonial, anti-patriarchal, and antihomophobic. Perhaps such a psychiatry even exists.

Then again, there are major differences between history and psychiatry. One involves a much more direct control of captive bodies. Psychiatry is in many ways closer to prisonFoucault has an interesting roundtable discussion published as "Psychiatry, Confinement, Prison," linking these three phenomena, and arguing (as he does in History of Madness) that psychoanalysis just takes the logic of psychiatry one step further. So there is a history of confinement and imprisonment involved in psychiatry, whereas the worst that historians do is to cover their foes in a lot of dust and silence them. Psychiatrists, as "scientists" or "doctors" (however much Foucault wanted to show that they were not really practicing medicine or science), also have a much more influential form of expertise in our society than historians. 
When there is a shooting in a high school, you don't have teams of historians called in to tell teachers and parents what to do, telling the students how to experience the event, or talking on the news about it, situating the event historically or giving us some kind of historical perspective on it. Psychiatrists are a lot more dangerous than historians at the moment, precisely because they masquerade as scientists and we are credulous of science. Perhaps this is what made all the difference for Foucault.

A last point about Fanon that connects to Foucault: although he tries to use psychiatry as an anti-colonial force, Fanon recognizes that it has its limits. Ultimately, for Fanon, talk therapies that take place between a doctor and a patient in a hospital aren't going to make much of a difference, so long as the patient leaves the hospital and the world is the same racist, colonial place that is was before. None of the case histories in The Wretched of the Earth ends with the patient being cured. After all, you're not going to undo the internalization of racism or the trauma of oppression and torture just by talking to a psychiatrist about it, but only by driving the Europeans out of your country, with violence if necessary-indeed preferably with violence. Famously, Fanon advocates political violence as therapeutic, more therapeutic than psy treatments. This reminds me of an important argument that Ladelle McWhorter makes in Bodies and Pleasures, when she argues that disciplinary power acts not so much on our minds as on our bodies, and thus, to resist it, to undo it, we would need tactics that operate less at the level of ideas than at the level of gestures, of the body (72). Your new book project is on philosophies of the body, and you have also discussed Foucault in relation to yogic practice at the end of SelfTransformations. I wonder if you might say something about your new book project, as it relates to Foucault and also departs from him, and whether you see the cognitive rather than corporeal focus of psychotherapies as making them unlikely tactics of resistance to disciplinary power? 
$\mathrm{CH}$ : I have been thinking a lot about this, but my ideas are still very under-developed. Alexis Shotwell is publishing a very interesting book on the political implications of extra-linguistic forms of knowledge (Knowing Otherwise), and when I asked her about her research for that work she commented that philosophy is way behind other disciplines, especially anthropology, in the way we think humanistically about the body. I think this is true, and could also be said of political theory, which is my other "home" discipline. Conversely, whenever I give talks with a body theme, I always get people in dance or performance asking me really good questions, in a slightly impatient, this-is-all-obvious kind of voice! Those who practice with their bodies, as you might expect, have forms of knowledge that don't translate easily into the written word.

I find Foucault paradoxical on this. On the one hand, he was clearly very interested in how our bodies are constituted through practices of power that can't be reduced to language: the architecture of surveillance, the discipline of anatomy, the confession of sexual desire. But his ambivalent hostility to the phenomenological tradition's emphasis on the essentials of lived experience, and his emphasis on assujettissement as an effect of power, combine to create the impression that he really doesn't think any philosophical insight can be gleaned from how we understand our bodies as individuals, or what we do with them at the level of individual practice. Then again, why his interest in SM, or good drugs, or limit-experiences, or bodily pleasure in general? A lot of scholars have puzzled over this, often under the rubric of whether or not there is a "break" between his genealogical and ethical work. I'm inclined to think that he was trying to historicize phenomenology rather than discard it, and that his later work on care of the self provides a different perspective on the same problematic, rather than a radical break from his analysis of biopower. 
So the new project is trying to work out all the details of this philosophical debate (just because I know Foucault and it's where my last book left off, really) and see whether it can allow me to get into this incredibly interdisciplinary literature on "body knowledge." My motivating question is partly epistemological, but also political: a lot of political philosophy likes to gesture toward "the body" as a factor in political life, but it does so terribly vaguely and with a great deal of dissociation. I'm a practical person, so I want to know: what do political practices do to our bodies (Foucault's question, too)? But further, what kinds of political effects do the bodily things we do-singly and collectively_have? A part of this is my interest-personal and intellectual — in therapeutic aspects of the question. There are schools of body psychotherapy —in the traditions of Wilhelm Reich or Gerda Boyesen, for example — and of course many body-mind practices like yoga or tai chi. If Foucault is right that disciplinary power constitutes the body, then we'll need to resist at the level of our bodies. That's why talking cures - no matter what their politics—-seem limited to me.

CT: On the other hand, pharmaceuticals, unlike psychoanalysis, do directly target the body, so I wonder how you think that the new pharmacology might have changed psychotherapies since the time that Foucault was writing. Has this major shift in psychiatric treatment made Foucault's arguments more or less relevant? To return to your paper on BDD, for instance, you give the example of the pharmaceutical treatment of Attention Deficit Hyperactivity Disorder (ADHD), writing that "the development and promotion of the drugs themselves may lead to the backformation of types of child - those who respond to the drug must 'have' the disease, the marketing of which encourages identification with the syndromes it purports to cure." You use this example to illustrate a point of Foucault's in Discipline and Punish - that disciplinary 
treatments, including psychiatric ones, produce the subjectivities that they then diagnosealthough, as you note, the ADHD diagnosis postdates him. This would suggest that pharmaceutical treatments are merely another tool of disciplinary power, extending rather than transforming it.

$\mathrm{CH}$ : I would like to think more about how to reconcile Foucault's infamous statement in an interview that "we have to do good drugs that can produce very intense pleasure" with his critiques of the politics of psychiatry, which now revolve around pharmaceutical treatment to a much greater degree and in a different way than in his lifetime. Psychotropic drugs are completely everyday now-prescribed for much milder conditions and a wider range of conditions than in the past, sought out by patients rather than imposed by psychiatrists, or even seen as a kind of enhancement rather than a treatment - in another echo of your earlier point about "abnormality" no longer being the object of psychiatry. SSRI-type antidepressants (like Prozac) are reputedly by far the largest expense borne by our own university's drug plan! These drugs are perfectly legal, of course, and normative in obvious ways. They're normalizing, too, in that doubled sense that Foucault outlines in Discipline and Punish: they make the population more homogenous, while at the same time making more people into individual medical cases, with diagnoses, symptoms, identities. The drug-subjectivity is enabling and constraining: a copious literature on Prozac-type drugs debates whether they are enforcing conformity to implicit standards for proper mood or behaviour, or enabling people to be who they really are, or freeing us from mental disorders to be productive citizens, and so on. Doing good humanistic work on these pressing social issues will be important, I think, because I find health scientific discourses so impoverished when it comes to mental health. And I think humanities types will 
have to involve ourselves more consistently in the medical literature, to avoid the fatuous dichotomy of "nature" versus "social construction." When physicalist psychiatrists start talking about what drugs do in our brains, I don't think we can just shrug, as if bodies (including brains) aren't part of the picture we're theorizing. At the same time, it would be nice if more of those psychiatrists could actually open themselves to the idea that they might have missed important insights into the history, politics, and presuppositions of their discipline.

CT: Todd May has argued that "the genealogical critique, while focusing upon existing psychological practice, does not necessarily apply to all conceivable psychological practice. Foucault's histories show that the practices of psychology in our culture, in combination with other practices of our culture, have had onerous political effects. This does not imply that any psychological practice in any culture-nor even that any psychological practice in our own culture-must be oppressive. There is strong reason to believe that alternative practices labeled 'psychological' will, in the historical moment in which we find ourselves, contribute to the problems already raised by existing psychological practice. That is because the general focus upon the self that psychology fosters has become deeply entwined with the projects of normalization and discipline. The argument, however, is not an a priori one. The problem is not with the nature of psychology but with the practices that go under its name and with the perspective to which those practices-from school psychology to personnel management to personality theory to self-development-have given rise" (58). It seems that many Foucault scholars agree with May, or think that, despite Foucault's own relentless and categorical critiques of the psy disciplines (he said, for instance, that life is not worth living if one cannot "kill" psychology ${ }^{1}$ !), psychoanalytic theory and psychotherapeutic practices can nevertheless be 
useful. Scholars such as Judith Butler fuse Foucauldian theory with psychoanalytic theory, without even addressing how this would have been problematic for Foucault. Similarly, Foucault scholars (as we are both anecdotally aware) are themselves frequent clients of psychological practitioners. Yet Lynne Huffer, in her 2010 book, Mad For Foucault, has argued that Foucault and Freud are irreconcilable, and that we must choose between Foucault and psychoanalysis, not only in our theorizing but, presumably, in our way of living. What do you think: must we choose between Freud and Foucault, or can they be reconciled both in our practices and our writings? Is the problem with psychology intrinsic, such that we must simply eschew it at all costs, or is it contingent, in which case we just need to develop better psychological treatments?

$\mathrm{CH}$ : I can't do justice to that very complex question here, but I suppose my conclusion would be that it's too late to eschew psychoanalysis, let alone all of our commitments to analysis of our psy selves. The weight of the forms of power Foucault theorized so well is carried by individuals, and often carried, for reasons he also provided, at the level of the psyche. I don't think we can intervene in that experience by providing large political analyses alone, or genealogies of the psy disciplines. Our everyday experience is about what I might nervously call our "mental health" - or lack thereof - and how we relate to others in the webs of power that make us who we are, and that we in turn can reinforce or redirect. There has to be a language for talking about that, and "care of the self," at least as Foucault represents it in his unfinished final project, is a bit too skimpy to do the job, in my view.

What do you think? Is there any way of reforming psychotherapy without simply extending the negative aspects of normalization for which Foucault thought it was a vehicle? And can you say more about your own work in The Culture of Confession (and since) on how 
you think Foucault's last work on care of the self stands in relation to the psychological sciences?

CT: I argued in The Culture of Confession that Foucault's final two volumes of The History of Sexuality — probably the only two books by Foucault that don't explicitly criticize psychiatryare nevertheless all about the psychological sciences in so far as they are extended attempts to explore non-psychologizing approaches to sexuality and subjectivity. In the interview where Foucault talks about "killing" psychology, he identifies this "killing" with "the art of living." So in these final books where he turns to an ethico-aesthetic approach to the self, I think he is trying to prepare the way for the murder of psychology by showing psychology's contingency, or by demonstrating that there exists or has existed an utterly other way of approaching the self - an aesthetic one - and thus that this murder is possible. Having critiqued the psy disciplines for over twenty years, I think that Foucault was now describing alternatives to them in these last works, even if psychoanalysis is never named. In this case, it is highly ironic to take psychoanalysis as a care of the self when Foucault was interested in exploring technologies of self-care as alternatives to the psy disciplines and as means for murdering psychology. And yet this is not to say that it cannot be done, and in fact, if you are right that it is too late to eschew psychoanalysis, perhaps this is precisely what needs to be done. If it weren't too late, however-and I am not sure that I agree that it is - I would be more interested in exploring, with Foucault, alternatives to psychological approaches to the subject and sexuality, such as the aesthetic, than with working within the psy approach in order to find less normalizing versions of it. 


\section{Notes}

1 'L'art de vivre, c'est de tuer la psychologie [...] Si on ne peut pas arriver à faire ça dans la vie, elle ne mérite pas d'être vécue" (Foucault 1071).

\section{Works Cited}

Fanon, Frantz. The Wretched of the Earth. New York: Grove Press, 2004.

Foucault, Michel. "Conversations avec Werner Schroeter.” Dits et écrits II. Paris: Gallimard, 2001: 1070-1079.

Heyes, Cressida J. "Diagnosing Culture: Body Dysmorphic Disorder and Cosmetic Surgery." Body \& Society 15.4 (2009): 73-93.

May, Todd. Between Genealogy and Epistemology: Psychology, Politics, and Knowledge in the Thought of Michel Foucault. University Park, Pennsylvania: Pennsylvania University Press: 1993.

Shotwell, Alexis. Knowing Otherwise: Implicit Understanding and Political Change. University Park, Pennsylvania: Pennsylvania State University Press, 2011.

Taylor, Chloë. "Fanon, Foucault, and the Politics of Psychiatry." Fanon and the Decolonization of Philosophy. Eds. Elizabeth Hoppe and Tracey Nicholls. Place of Pub: Lexington P, 2010. 55-74.

Toews, John E. "Foucault and the Freudian Subject." Foucault and the Writing of History. Ed. Jan Goldstein. Oxford: Blackwell, 1994. 116-134.

Whorter, Ladelle. Bodies and Pleasures: Foucault and the Politics of Sexual Normalization. Bloomington: Indiana UP, 1999.

O’Grady, Helen. Woman's Relationship with Herself: Gender, Foucault, and Therapy. London and New York: Routledge, 2005. 